\title{
Enhanced Two-Photon Absorption of Cross- Conjugated Chalcone Derivatives: Modulation of the Effective $\pi$-Conjugated Structure
}

\section{Supporting Information}

Jidong Jia, ${ }^{\dagger}$ Xueru Zhang, ${ }^{*}{ }^{\dagger}$ Yuxiao Wang, ${ }^{\dagger}$ Yufang Shi, ${ }^{\ddagger}$ Jinyu Sun, ${ }^{\ddagger}$ Junyi Yang, ${ }^{\S}$ and Yinglin Song ${ }^{*, \dagger, \S}$

${ }^{\dagger}$ Department of Physics, Harbin Institute of Technology, Harbin150001, China

$\$$ Department of Chemistry, Xinzhou Teachers University, Xinzhou 034000, China

$\S$ Department of Physics, Soochow University, Suzhou 215123, China

\section{Table of contents}

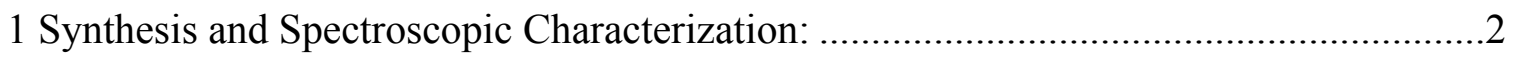

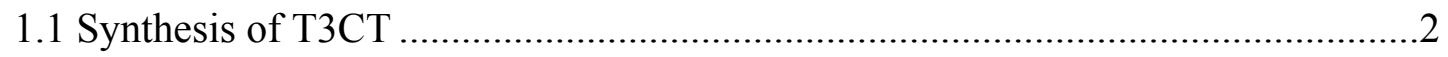

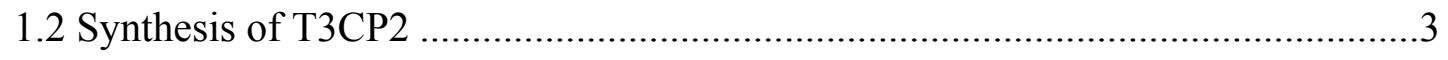

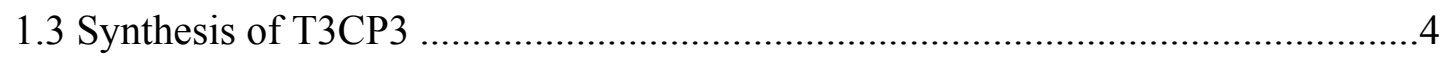

2 Femtosecond Z-scan experiment under different incident light intensity .......................11

3 Transient absorption spectral evolution of T3CT and T3CP3 ....................................12

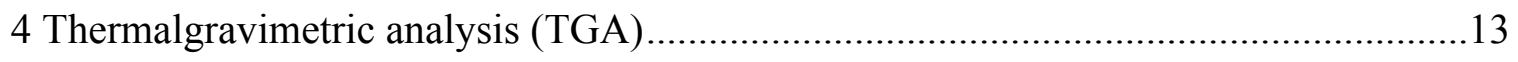


1 Synthesis and Spectroscopic Characterization:

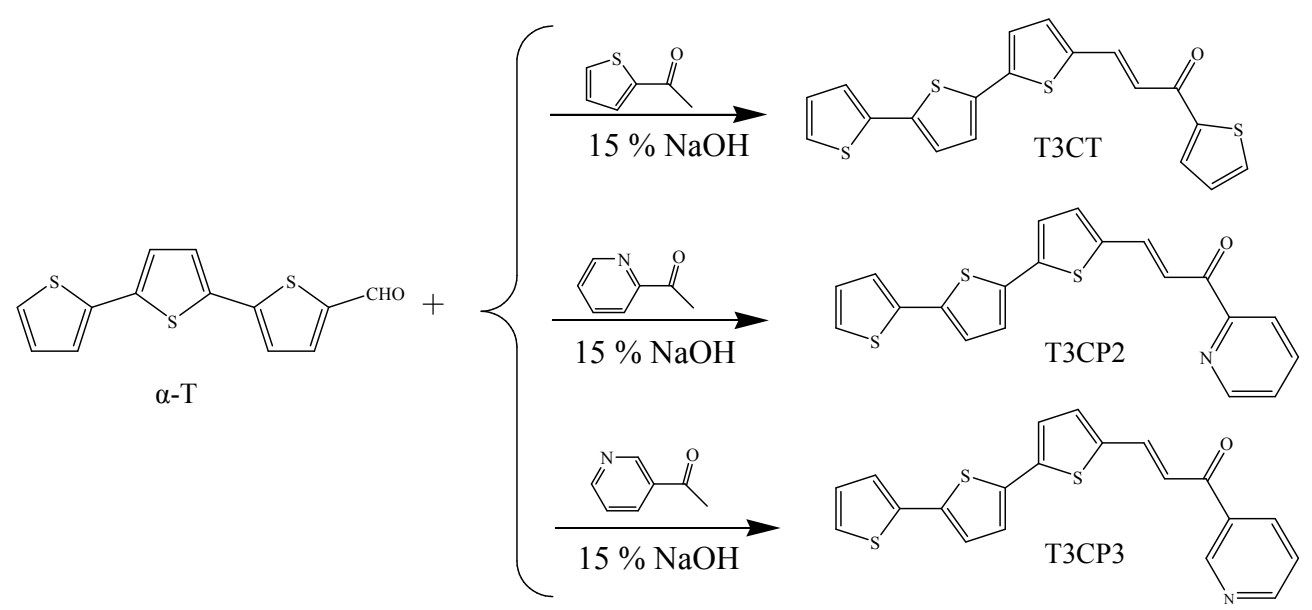

Scheme S1. Synthetic route of chalcone derivatives T3CT, T3CP2 and T3CP3

1.1 Synthesis of T3CT ((E)-1-(thiophen-2-yl)-3-(5-(5-(thiophen-2-yl)thiophen-2yl)thiophen-2-yl)prop-2-en-1-one)

A mixture of $\alpha$-terthiophene-carbaldehyde $(\alpha-\mathrm{T}, 0.08 \mathrm{~g}, 0.3 \mathrm{mmol})$, and absolute ethanol $(30 \mathrm{~mL})$ was placed in a $100 \mathrm{~mL}$ single neck round bottom flask. Heat the ethanol solution in the flask until $\alpha-\mathrm{T}$ is completely dissolved under magnetic stirring. Then add 2-acetothiophene $(100 \mu \mathrm{L}, 0.9 \mathrm{mmol})$ and $15 \% \mathrm{NaOH}$ aqueous solution $(1 \mathrm{~mL})$ and react for $1 \mathrm{~h}$. Continue to stir and heat to reflux for 24 hours until the reaction is complete (TLC follows the reaction process, $\mathrm{V}_{\text {ethyl acetate }}$ $\mathrm{V}_{\text {petroleum ether }}=1: 5$ ). After cooling and vacuum filtration, the filter cake was washed with absolute ethanol and dried in a vacuum drying oven (TLC detects the target product $\mathrm{V}_{\text {ethyl acetate }} \mathrm{V}_{\text {petroleum ether }}=1: 5, \mathrm{R}_{\mathrm{f}}=0.54$ ). 
Finally, $0.07 \mathrm{~g}$ of red powdered solid was obtained, and the sample yield was $60.8 \%$. ${ }^{1} \mathrm{H}$ NMR $\delta /$ ppm (600 MHz, DMSO- $d$ ): 8.275(s, 1H), 8.065 8.057(d, $1 \mathrm{H}, J=4.8 \mathrm{~Hz})$, 7.896 7.870(d, 1H, $J=15.6 \mathrm{~Hz}$, olefince-H), 7.677(s, 1H), 7.587 7.579(d, $1 \mathrm{H}, J=$ 4.8Hz), 7.518 7.493(d, 1H, J=15Hz, olefince-H), 7.457(s, 1H), 7.438(s, 1H), 7.402(s, 1H), $7.352(\mathrm{~s}, 1 \mathrm{H}), 7.312(\mathrm{~s}, 1 \mathrm{H}), 7.136(\mathrm{~s}, 1 \mathrm{H}) .{ }^{13} \mathrm{C}$ NMR $\delta / \mathrm{ppm}(150 \mathrm{MHz}$, DMSOd):181.35, 145.86, 140.12, 138.90, 137.31, 136.16, 135.99, 135.94, 135.26, 134.91, 133.88, 129.44, 129.06, 126.93, 126.73, 125.88, 125.76, 125.25, 120.64. MS (FTMS, m/z), calc. for $\mathrm{C}_{19} \mathrm{H}_{12} \mathrm{OS}_{4}: 383.9771$; found $384.9851[\mathrm{M}+\mathrm{H}]^{+}$. (Shown in Figure S1-S3)

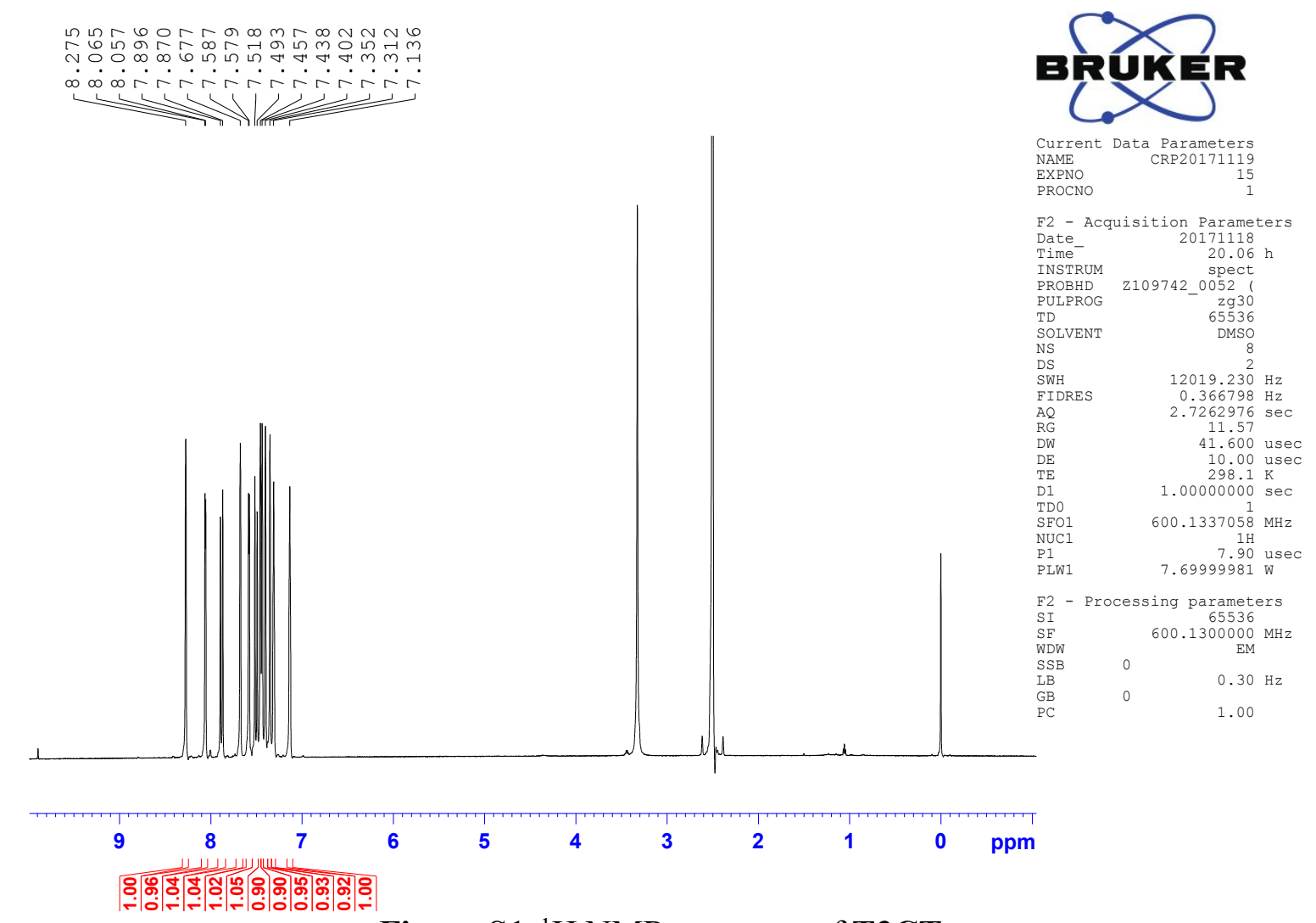

Figure S1. ${ }^{1} \mathrm{H}$ NMR spectrum of T3CT. 

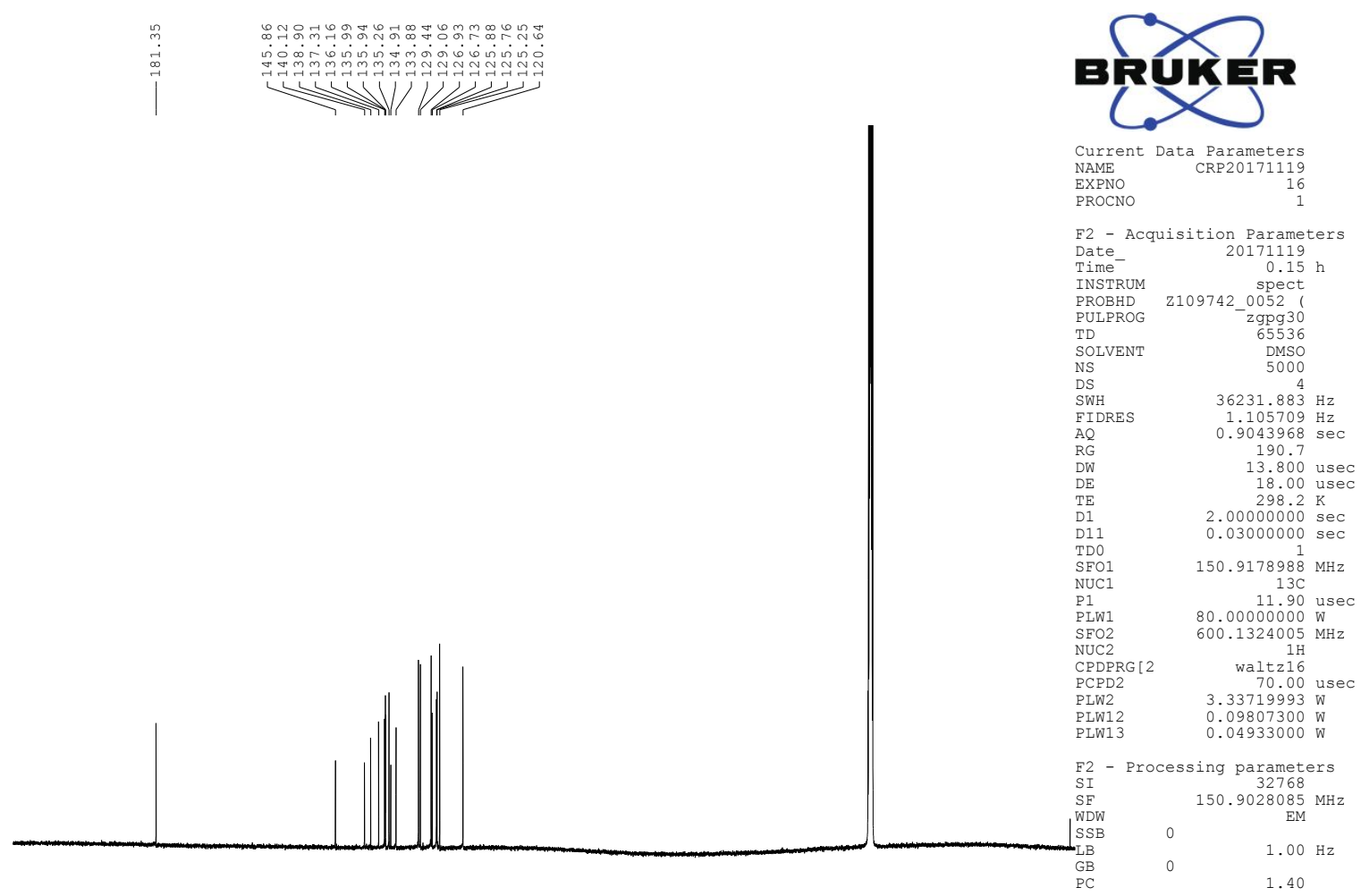

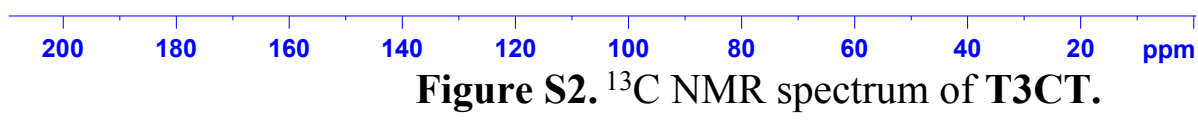

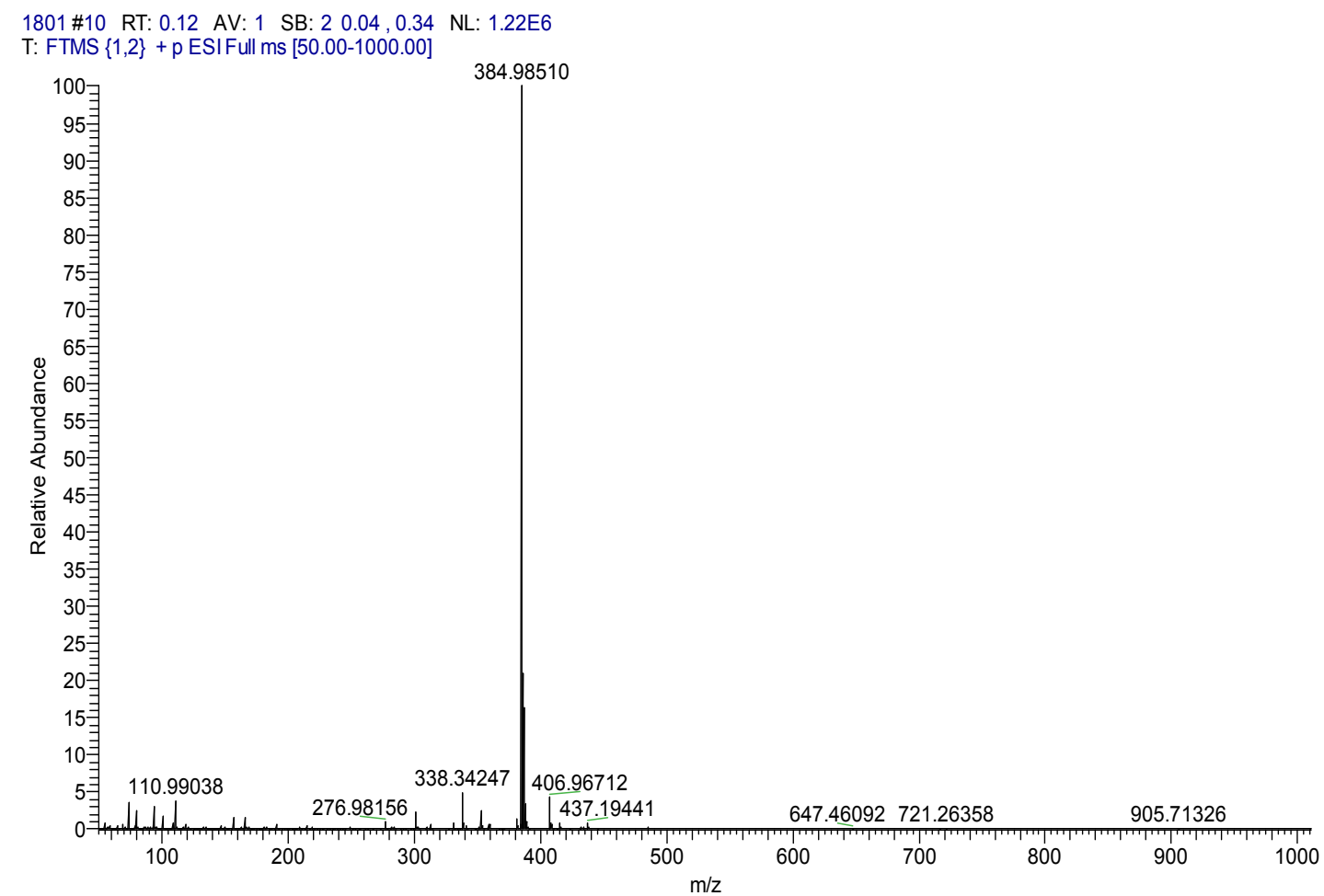

Figure S3. MS spectrum of T3CT 
1.2 Synthesis of T3CP2 ((E)-1-(pyridin-2-yl)-3-(5-(5-(thiophen-2-yl)thiophen-2yl)thiophen-2-yl)prop-2-en-1-one):

A mixture of $\alpha$-terthiophene-carbaldehyde ( $\alpha$-T, $0.27 \mathrm{~g}, 1 \mathrm{mmol})$ and absolute ethanol (30 $\mathrm{mL}$ ) was placed in a $250 \mathrm{~mL}$ three-necked round bottom flask with a spherical reflux device. Heat the ethanol solution in the flask until $\alpha-T$ is completely dissolved under magnetic stirring. Then add 2-acetylpyridine (336 $\mu \mathrm{L}, 3 \mathrm{mmol})$ and $15 \% \mathrm{NaOH}$ aqueous solution $(1 \mathrm{~mL})$ and react for $1 \mathrm{~h}$. Continue to stir and heat to reflux for 24 hours until the reaction is complete (TLC follows the reaction process, $V_{\text {ethyl acetate }} V_{\text {petroleum ether }}=1: 6$ ). After cooling and vacuum filtration, the filter cake was washed with absolute ethanol and dried in a vacuum drying oven (TLC detects the target product $\mathrm{V}_{\text {ethyl acetate }}: \mathrm{V}_{\text {petroleum ether }}=$ $\left.1: 6, \mathrm{R}_{\mathrm{f}}=0.51\right)$. Finally, $0.26 \mathrm{~g}$ of orange-red powdered solid was obtained, and the sample yield was 68.6\%. ${ }^{1} \mathrm{H}$ NMR $\delta / \mathrm{ppm}(600 \mathrm{MHz}$, DMSO-d): 8.818 8.811(d, $1 \mathrm{H}, J=$ $4.2 \mathrm{~Hz}), 8.114 \sim 8.101(\mathrm{~d}, 1 \mathrm{H}, J=7.8 \mathrm{~Hz}), 8.074 \sim 8.046(\mathrm{~m}, 1 \mathrm{H}), 8.033 \sim 8.006(\mathrm{~d}, 1 \mathrm{H}, J=$ $16.2 \mathrm{~Hz}$, olefince-H), 7.979 7.952(d, $1 \mathrm{H}, J=16.2 \mathrm{~Hz}$, olefince-H), 7.718 7.704(m, 1H), 7.698 7.696(d, $1 \mathrm{H}, J=1.2 \mathrm{~Hz}), 7.669 \sim 7.662(\mathrm{~d}, 1 \mathrm{H}, J=4.2 \mathrm{~Hz}), 7.591 \sim 7.581(\mathrm{t}$, $1 \mathrm{H}, J=3.0 \mathrm{~Hz}), 7.492 \sim 7.486(\mathrm{~d}, 1 \mathrm{H}, J=3.6 \mathrm{~Hz}), 7.449 \sim 7.443(\mathrm{~d}, 1 \mathrm{H}, J=3.6 \mathrm{~Hz})$, 7.412 7.405(m, 1H), 7.359 7.130(m, 1H). ${ }^{13} \mathrm{C}$ NMR $\delta / p p m(150 \mathrm{MHz}$, DMSO-d):188.27, $153.71,149.70,140.11,139.37,138.27,137.53,136.85,136.15,136.02,134.78,129.06$, 128.14, 127.33, 126.77, 126.00, 125.75, 125.29, 122.84, 119.49. MS (FTMS, m/z), calc. for $\mathrm{C}_{20} \mathrm{H}_{13} \mathrm{NOS}_{3}$ : 379.01593 ; found 380.02391 [M + H] $]^{+}$. (Shown in Figure S4-S6) 


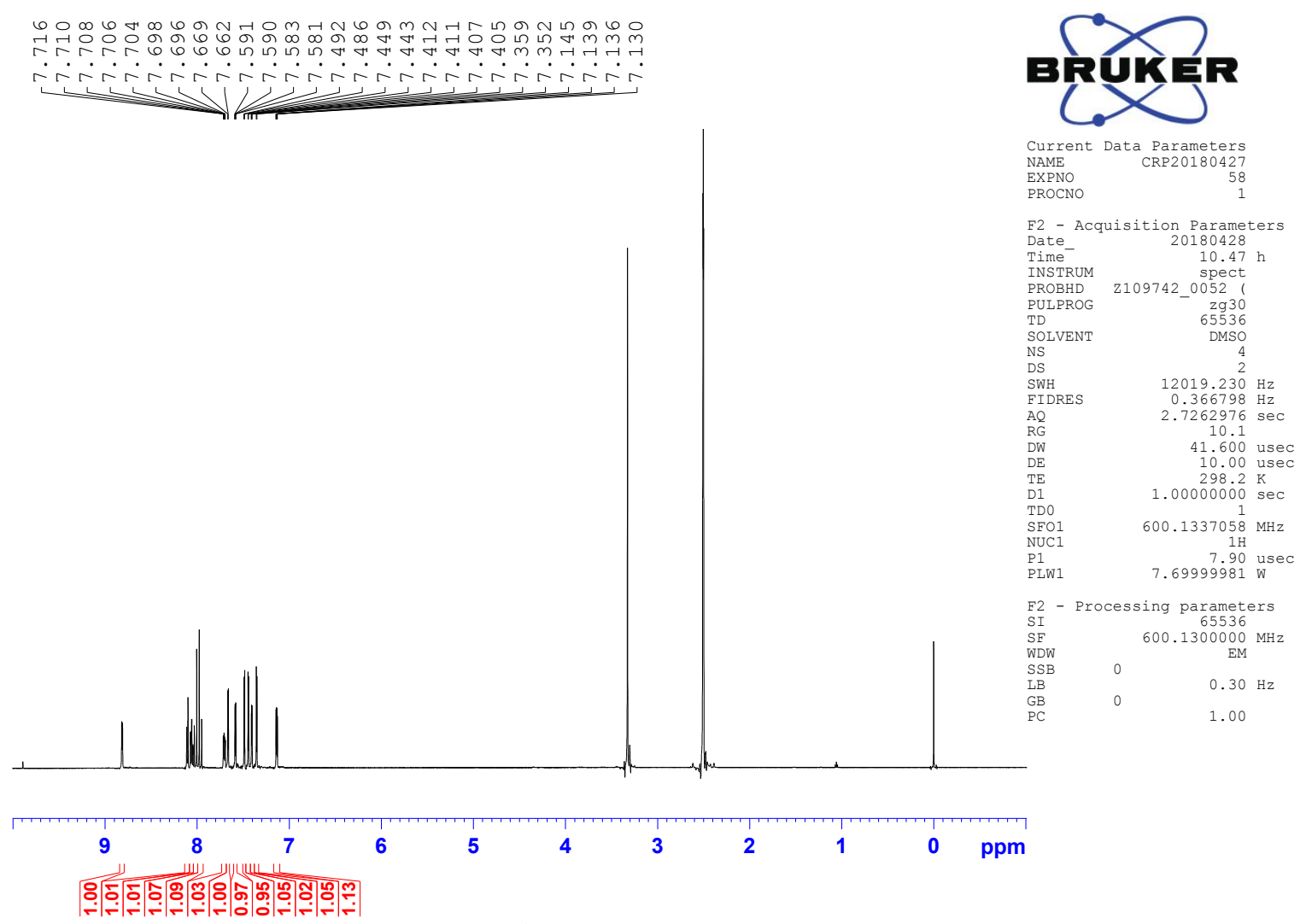

Figure S4. ${ }^{1} \mathrm{H}$ NMR spectrum of T3CP2.

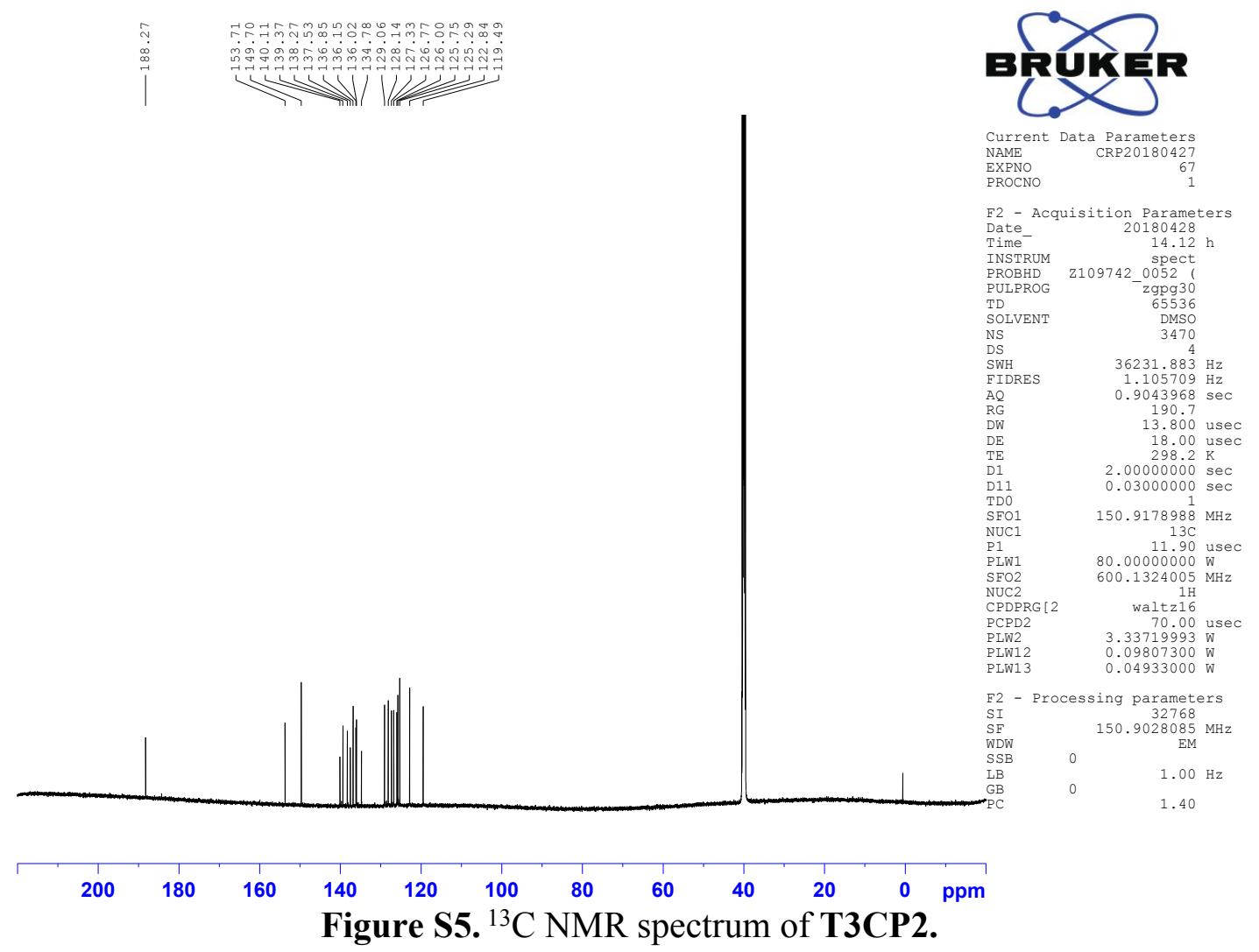




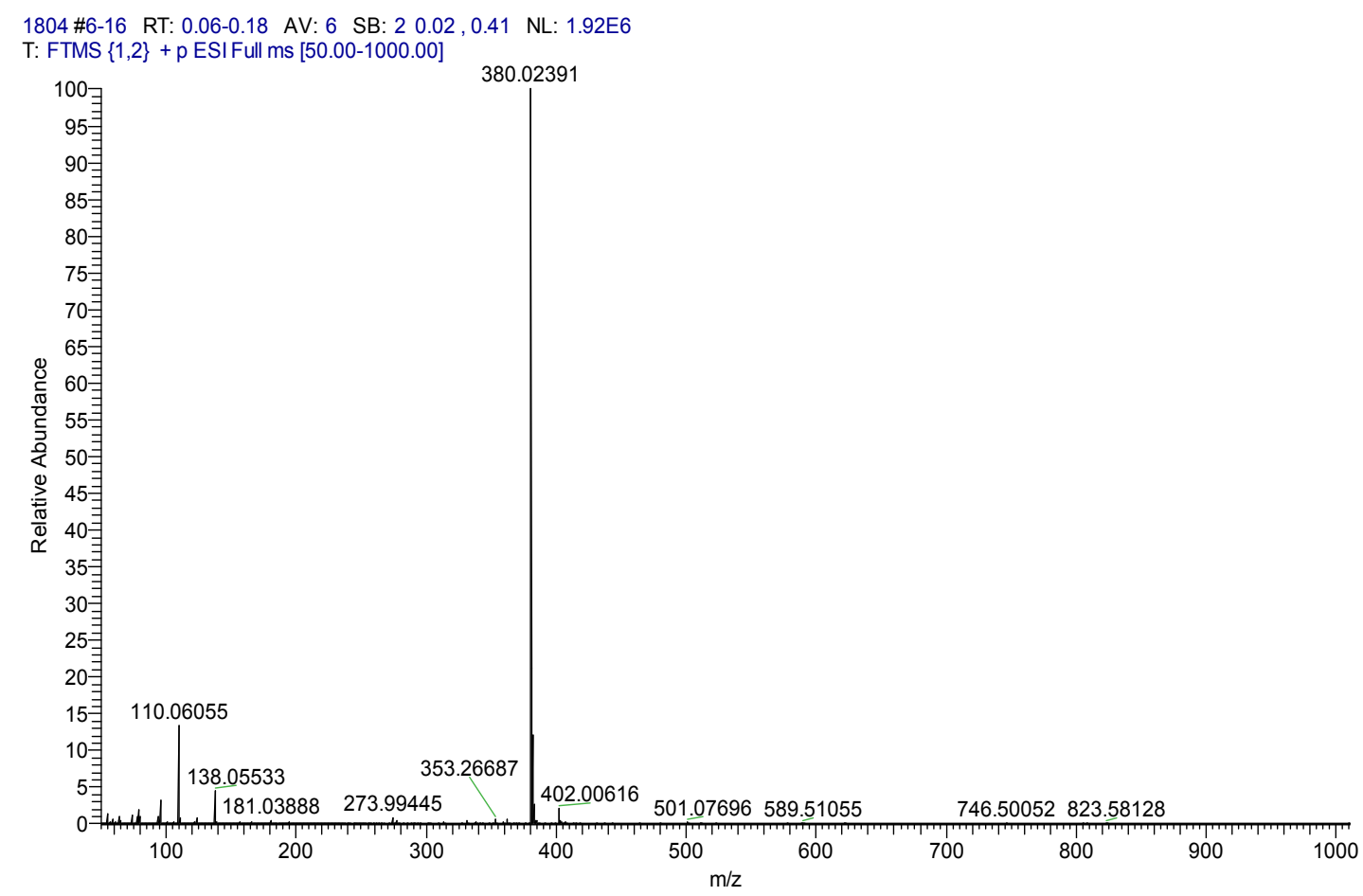

Figure S6. MS spectrum of T3CP2

1.3 Synthesis of T3CP3 ((E)-1-(pyridin-3-yl)-3-(5-(5-(thiophen-2-yl)thiophen-2yl)thiophen-2-yl)prop-2-en-1-one):

A mixture of $\alpha$-terthiophene-carbaldehyde $(\alpha-\mathrm{T}, 0.27 \mathrm{~g}, 1 \mathrm{mmol})$ and absolute ethanol (80 $\mathrm{mL}$ ) was placed in a $250 \mathrm{~mL}$ round bottom flask with a spherical reflux device. Heat the ethanol solution in the flask until $\alpha-\mathrm{T}$ is completely dissolved under magnetic stirring. Then add 3-acetylpyridine $(220 \mu \mathrm{L}, 2 \mathrm{mmol})$ and $15 \% \mathrm{NaOH}$ aqueous solution $(1 \mathrm{~mL})$ and react for $1 \mathrm{~h}$. Continue to stir and heat to reflux for 24 hours until the reaction is complete (TLC follows the reaction process, $V_{\text {ethyl acetate }} \mathrm{V}_{\text {petroleum ether }}=1: 6$ ). After cooling and vacuum filtration, the filter cake was washed with absolute ethanol and dried in a vacuum drying oven (TLC detects the target product $\mathrm{V}_{\text {ethyl acetate }}: \mathrm{V}_{\text {petroleum ether }}=1: 1$, $\mathrm{R}_{\mathrm{f}}=0.54$ ). Finally, $0.17 \mathrm{~g}$ of orange-red powdered solid was obtained, and the sample 
yield was $44.9 \%$. ${ }^{1} \mathrm{H}$ NMR $\delta / \mathrm{ppm}(600 \mathrm{MHz}$, DMSO- $d$ ): $8.819 \sim 8.811(\mathrm{~d}, 1 \mathrm{H}, J=4.8 \mathrm{~Hz})$, $8.115 \sim 8.102(\mathrm{~d}, 1 \mathrm{H}, J=7.8 \mathrm{~Hz}), 8.075 \sim 8.047(\mathrm{~m}, 1 \mathrm{H}), 8.034 \sim 8.008(\mathrm{~d}, 1 \mathrm{H}, J=15.6 \mathrm{~Hz}$, olefince-H), 7.980 7.954(d, 1H, $J=15.6 \mathrm{~Hz}$, olefince-H), 7.719 7.697(m, 1H), 7.670 7.664(d, 1H, $J=3.6 \mathrm{~Hz}), 7.592 \sim 7.582(\mathrm{q}, 1 \mathrm{H}, J=2.0 \mathrm{~Hz}), 7.494 \sim 7.487(\mathrm{~d}, 1 \mathrm{H}, J=$ $4.2 \mathrm{~Hz}), 7.451 \sim 7.445(\mathrm{~d}, 1 \mathrm{H}, J=3.6 \mathrm{~Hz}), 7.414 \sim 7.406(\mathrm{q}, 1 \mathrm{H}, J=1.6 \mathrm{~Hz}), 7.360 \sim 7.354(\mathrm{~d}$, $1 \mathrm{H}, J=3.6 \mathrm{~Hz}), 7.146 \sim 7.131(\mathrm{q}, 1 \mathrm{H}, J=3.0 \mathrm{~Hz})$. MS (FTMS, m/z), calc. for $\mathrm{C}_{20} \mathrm{H}_{13} \mathrm{NOS}_{3}$ : 379.01593; found $380.02389[\mathrm{M}+\mathrm{H}]^{+}$. (Shown in Figure S7-S9)

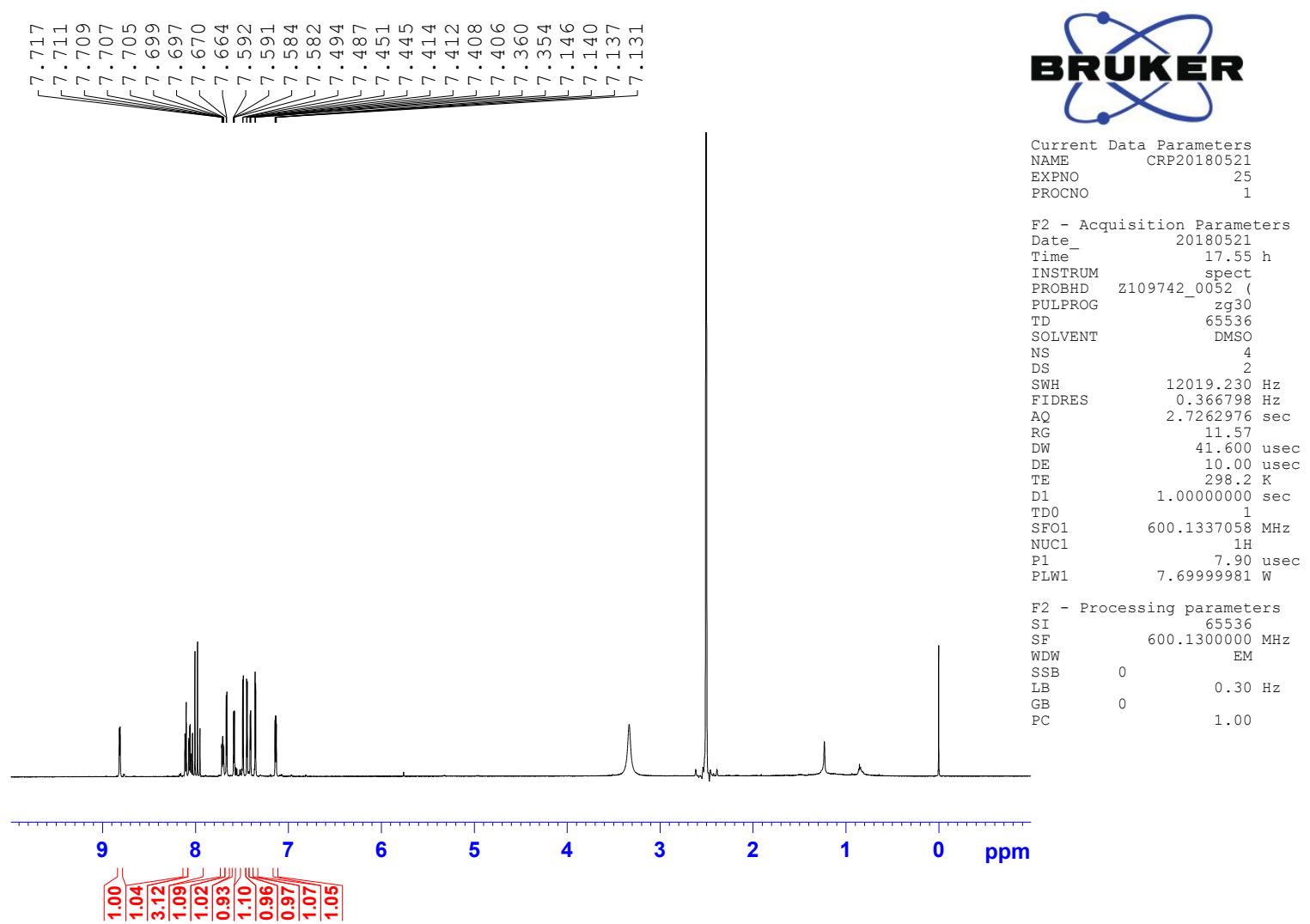

Figure S7. ${ }^{1} \mathrm{H}$ NMR spectrum of T3CP3. 


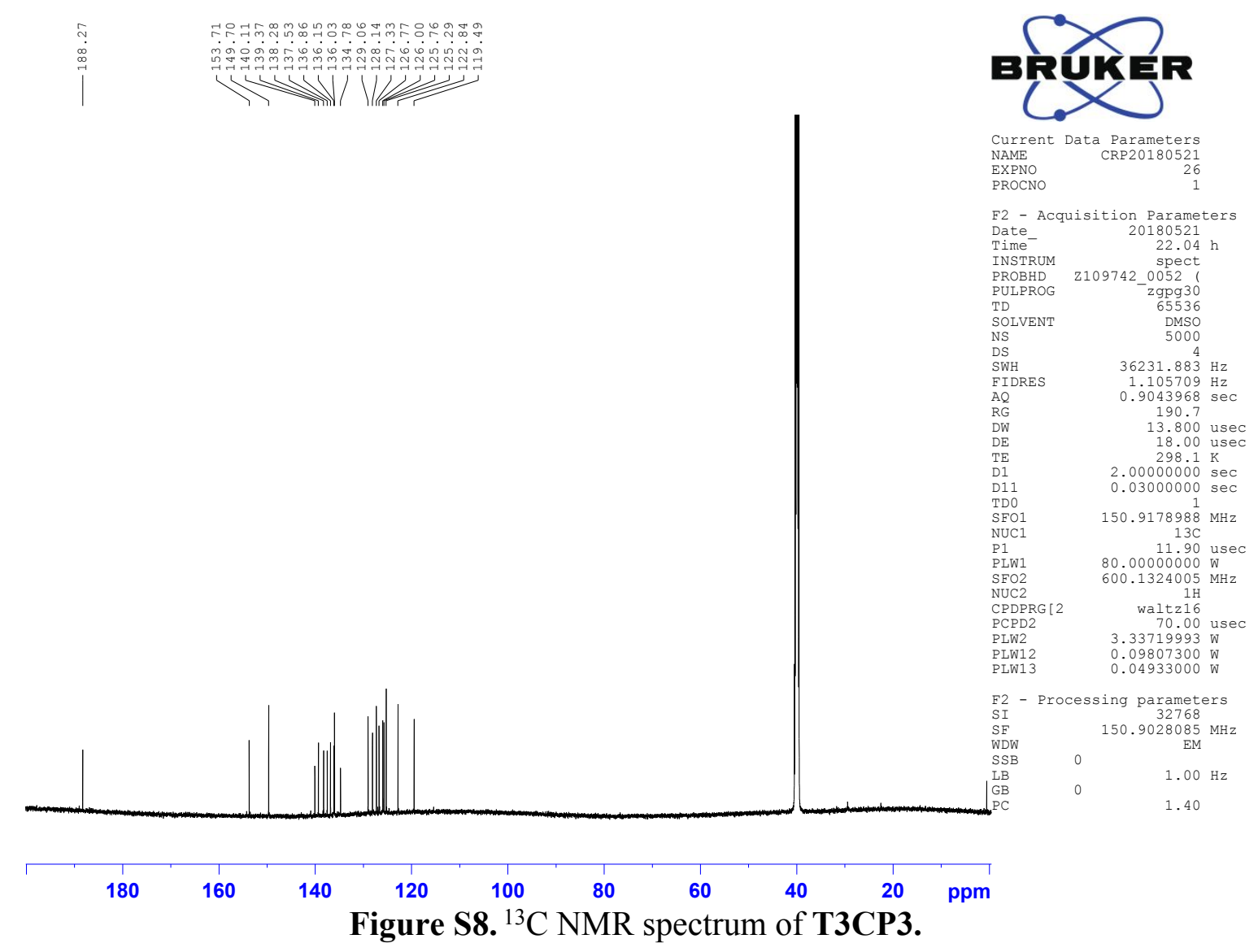

1805 \#6-15 RT: 0.07-0.16 AV: 5 SB: $20.04,0.34$ NL: $1.52 E 6$

T: FTMS $\{1,2\}+p$ ESI Full ms [50.00-1000.00]

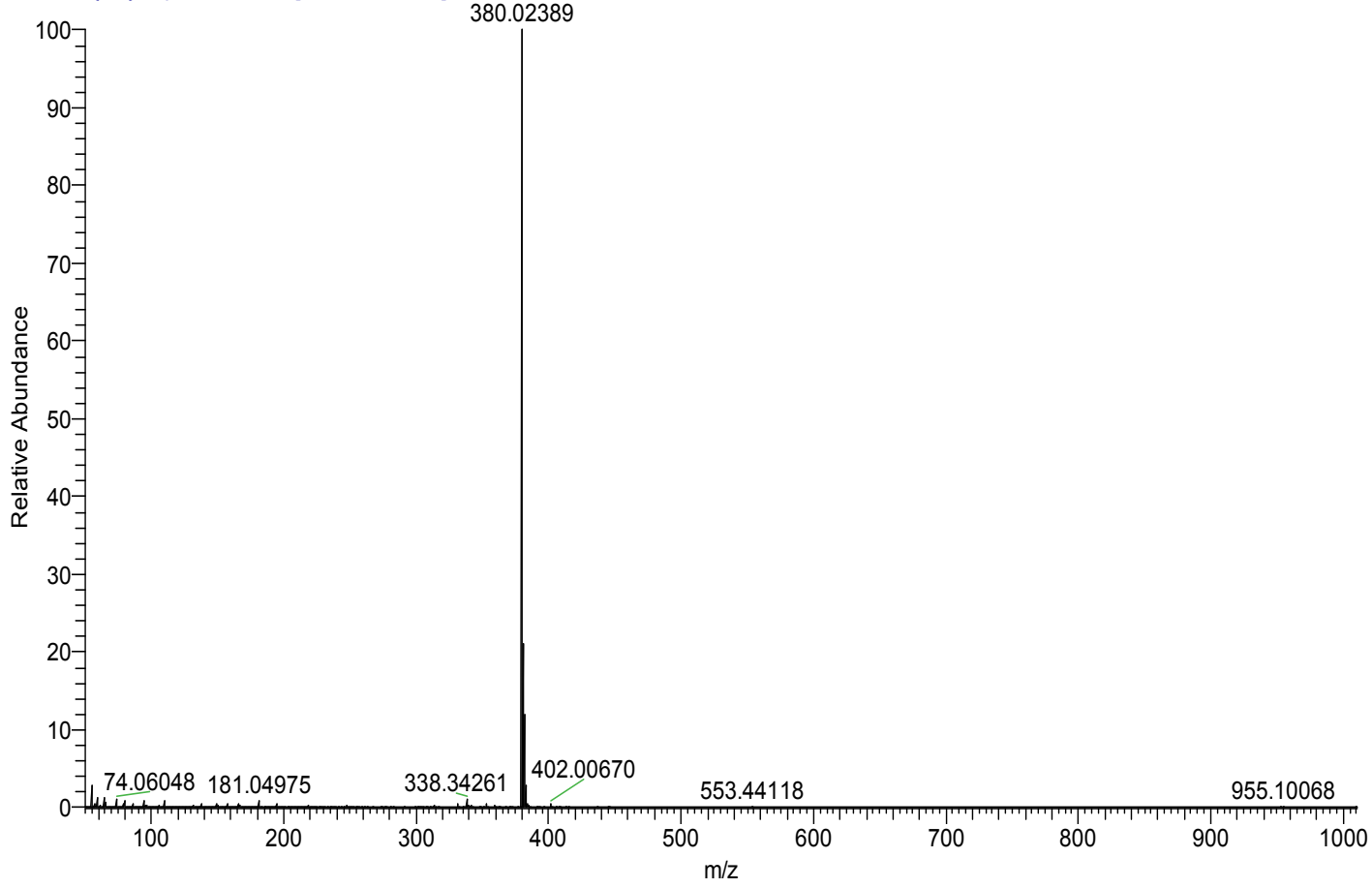

Figure S9. MS spectrum of T3CP3 
2 Femtosecond Z-scan experiment under different incident light intensity

(a) $580 \mathrm{~nm}$
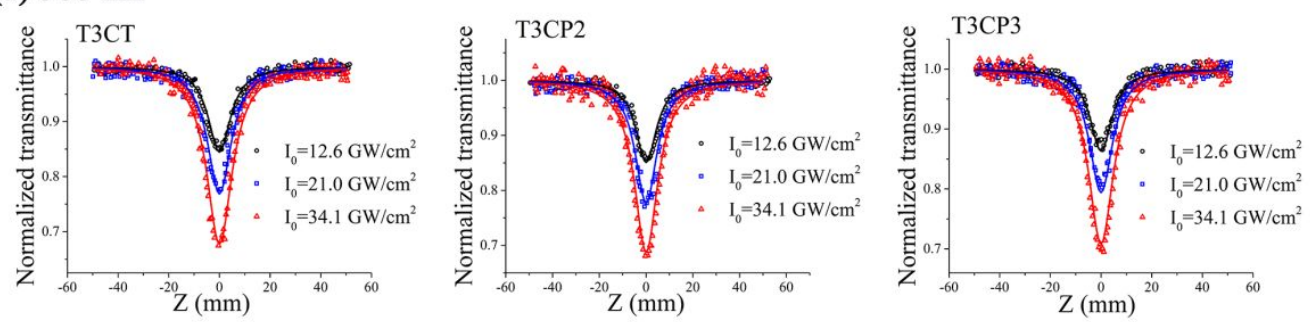

(b) $650 \mathrm{~nm}$
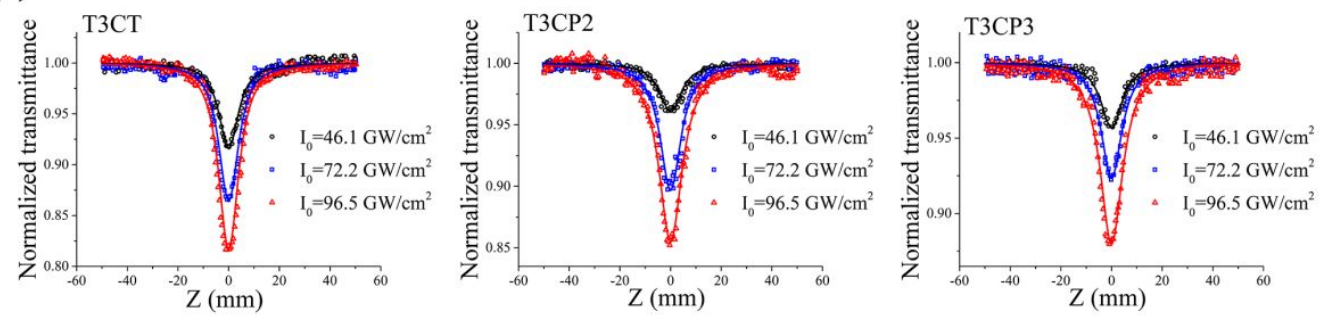

(c) $750 \mathrm{~nm}$
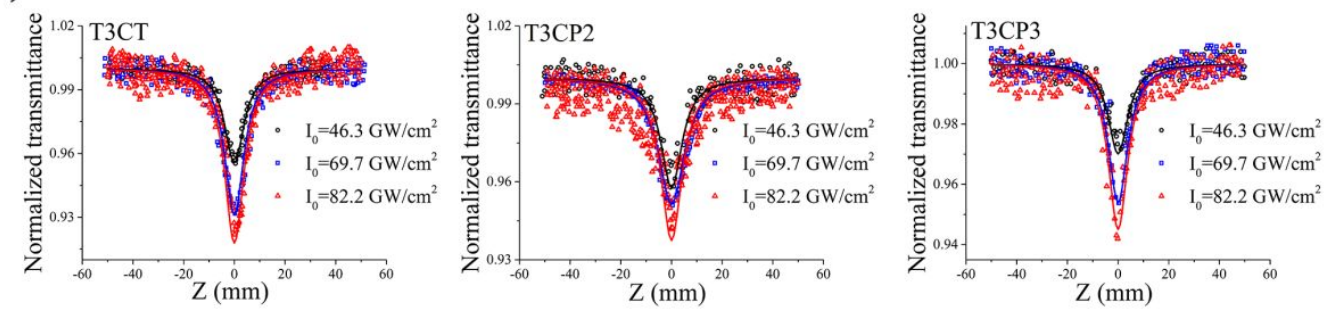

Figure S10. Femtosecond multi-wavelength Z-scan experiments of T3CT, T3CP2 and T3CP3 under different incident light intensity.

Table S1. The fitting parameters of T3CT, T3CP2 and T3CP3 in the femtosecond Zscan experiment. $\beta_{\text {eff }}$ is the effective RSA coefficient.

\begin{tabular}{|c|c|c|c|c|}
\hline & & T3CT & T3CP2 & T3CP3 \\
\hline $\begin{array}{l}\text { Wavelength } \\
\text { (nm) }\end{array}$ & $\begin{array}{c}\mathrm{I}_{0} \\
\left(\mathrm{GW} / \mathrm{cm}^{2}\right)\end{array}$ & $\begin{array}{c}\beta_{\text {eff }} \\
\left(10^{-2} \mathrm{~cm} / \mathrm{GW}\right)\end{array}$ & $\begin{array}{c}\beta_{\text {eff }} \\
\left(10^{-2} \mathrm{~cm} / \mathrm{GW}\right)\end{array}$ & $\begin{array}{c}\beta_{\text {eff }} \\
\left(10^{-2} \mathrm{~cm} / \mathrm{GW}\right)\end{array}$ \\
\hline \multirow{3}{*}{580} & 12.6 & 22.0 & 21.0 & 19.0 \\
\hline & 21.0 & 23.0 & 23.0 & 20.0 \\
\hline & 34.1 & 26.0 & 25.0 & 22.0 \\
\hline \multirow{3}{*}{650} & 46.1 & 2.60 & 1.30 & 1.40 \\
\hline & 72.2 & 3.20 & 2.40 & 1.70 \\
\hline & 96.5 & 3.50 & 2.80 & 2.10 \\
\hline \multirow{3}{*}{750} & 46.3 & 1.40 & 1.05 & 0.95 \\
\hline & 69.7 & 1.50 & 1.10 & 1.00 \\
\hline & 82.2 & 1.60 & 1.20 & 1.10 \\
\hline
\end{tabular}




\section{Transient absorption spectral evolution of T3CT and T3CP3}
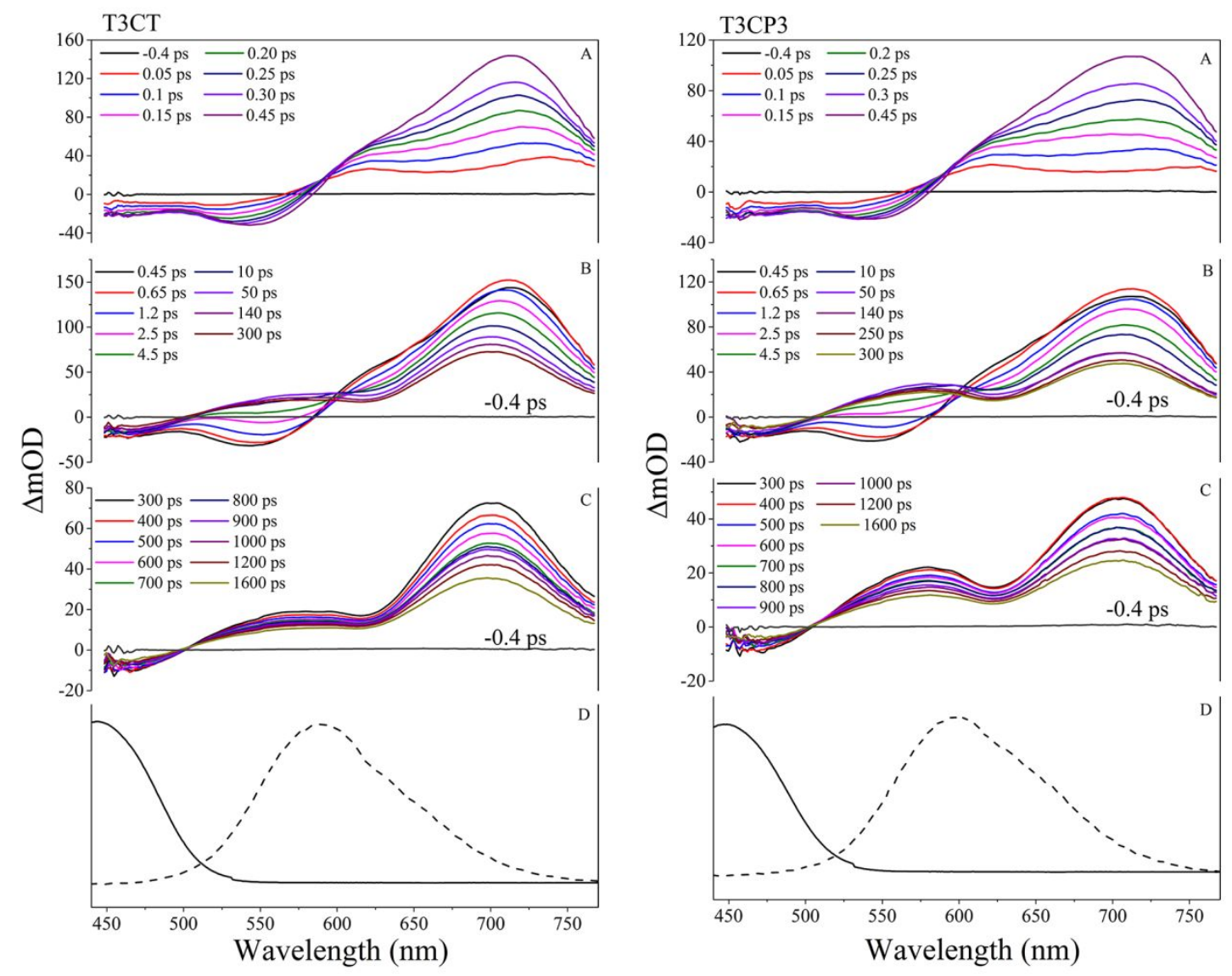

Figure S11. TAS of T3CT and T3CP3 at different time delays excited by femtosecond laser pulses. The spectral evolution is divided into four time domains $0-0.45 \mathrm{ps}$ (A), 0.45300 ps (B) and 300-1600 ps (C). Reference steady-state absorption (solid line) and fluorescence (dashed line) of T3CT and T3CP3 are also given (D).

TAS of T3CT and T3CP3 are extremely similar as T3CP2 (Shown in Figure 6). Detailed description can be found in the manuscript (See Section 3.3). The spectral evolution of T3CT and T3CP3 is divided into three parts. The first relaxation step (0$0.45 \mathrm{ps}$ ) is assigned to some conformational relaxation from $\mathrm{FC}$ level toward $\mathrm{S}_{1}(\mathrm{ICT})$ equilibrium geometry. The second relaxation step $(0.45-300 \mathrm{ps})$ is assigned to solvation relaxation and conformational rearrangement $\left(\mathrm{S}_{1}(\mathrm{ICT}) \rightarrow \mathrm{S}_{1}\left(\mathrm{ICT}^{\prime}\right)\right)$. The final relaxation step (300-1600 ps) is designated as the conformational relaxation $\left(\mathrm{S}_{1}\left(\mathrm{ICT}^{\prime}\right) \rightarrow \mathrm{S}_{0}\right)$ from 
the twisted structure of the ICT' state to the ground state equilibrium structure along with the vibration cooling process.

\section{Thermalgravimetric analysis (TGA)}

We further performed the thermalgravimetric analysis (TGA) experiment to study the thermal stability of T3CT, T3CP2 and T3CP3, shown in Figure S12. TGA experiment was performed under nitrogen atmosphere. The onset temperature of weight loss were $263{ }^{\circ} \mathrm{C}$ for $\mathrm{T} 3 \mathrm{CT}, 214{ }^{\circ} \mathrm{C}$ for $\mathrm{T} 3 \mathrm{CP} 2$ and $260{ }^{\circ} \mathrm{C}$ for $\mathrm{T} 3 \mathrm{CP} 3$, indicating a good thermal stability.
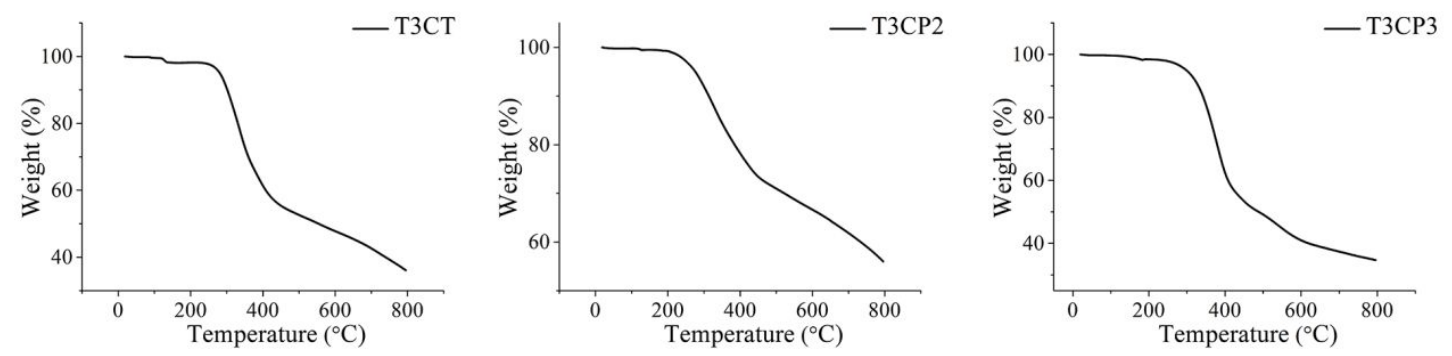

Figure S12. TGA of T3CT, T3CP2 and T3CP3 